\title{
Porocarcinoma Ecrino: Reporte de un caso.
}

Rosario Alarcón C'1, Juan P Morales E², Patricio Llancapi V³ , Carolina Delgado Sch'.

'Dermatóloga. Facultad de Medicina. U. de Concepción; ${ }^{2}$ Médico General de Zona Hospital Puerto Saavedra; ${ }^{3}$ Dermatólogo. Hospital Gmo. Grant Benavente. Concepción; ${ }^{\circledR}$ Patóloga. Facultad de Medicina. U. de Concepción. Chile.

\section{Resumen}

Los tumores anexiales de la piel representan un grupo heterogéneo de entidades de baja frecuencia de presentación. Su origen es controvertido, quizás a partir de células madres pluripotenciales, aceptándose principalmente dos líneas embriológicas: pilosebáceo-apócrina y ecrina. Se los clasifica en cuatro grupos principales: tumores del folículo piloso, tumores sebáceos, tumores apócrinos y tumores ecrinos. Su distribución anatómica refleja áreas con mayor densidad de anexos cutáneos, presentándose en forma única o múltiple.

Palabras claves: Porocarcinoma, tumor anexial, metástasis, quimioterapia, radioterapia.

\section{Summary}

Skin adnexal tumors are represented as a heterogeneous group of entities of low frequency range. Its origin is controversial, perhaps from pluripotent stem cells, mainly from two embryological lines: pilosebaceous-apocrine and eccrine. They are classified as four main groups: tumors of the hair follicle, sebaceous tumors, apocrine tumors and eccrine tumors. Their anatomic distribution reflects areas with the highest density of cutaneous adnexal, arising in either single or multiple forms.

Key words: Porocarcinoma, skin adnexal tumor, metastasis, chemotherapy, radiotherapy.

\section{Introducción}

Los tumores anexiales de la piel representan un grupo heterogéneo de entidades de baja frecuencia de presentación, los cuales en determinados casos pueden plantear ciertas dificultades diagnósticas para el dermatólogo y el patólogo, implicando un desafío en su reconocimiento. Su origen es controvertido, quizás a partir de células madres pluripotenciales, aceptándose principalmente dos líneas embriológicas: pilosebáceo-apócrina y ecrina ${ }^{1,2}$. Con fines prácticos se clasifican en cuatro grupos principales, según su diferenciación en los diferentes anexos cutáneos: tumores del folículo piloso, tumores sebáceos, tumores apócrinos y tumores ecrinos ${ }^{3}$. Su distribución anatómica refleja áreas con mayor densidad de anexos cutáneos, presentándose en forma única o múltiple.

El porocarcinoma ecrino, llamado también poroma ecrino maligno, es una neoplasia maligna rara que representa menos del $0.01 \%$ de todos los tumores cutáneos epiteliales, siendo el tumor más común desarrollado a partir de la porción intraepidérmica de la glándula sudorípara ecrina (acrosiringio) ${ }^{4}$.
Esta entidad fue descrita por primera vez en 1963 por Pinkus y Mehregan, llamándole "carcinoma ecrino epidermotrópico", posteriormente, en 1969, Mishima y Morioka le dieron la denominación actual ${ }^{5}$. Menos de 300 casos se han informado en todo el mundo desde que fue descrita por primera vez en 1963, alrededor de la mitad en las extremidades inferiores (44\%-53\%), aunque también se han descrito en tronco $(24 \%)$, cabeza (18\%) y extremidades superiores $(8 \%)$. Sin embargo, cualquier área puede ser afectada ${ }^{6}$.

\section{Caso Clínico}

Varón de 65 años, procedente de Concepción, quien trabaja como bodeguero en una mina de Tarapacá, con antecedentes de hipertensión arterial en tratamiento con losartán. Consulta en enero de 2012 porque en piel de región inguinal derecha, presentaba una lesión nodular eritematosa de $1 \mathrm{~cm}$ de diámetro aproximadamente, de borde regular, asintomática, asociada a aumento de volumen de la extremidad inferior derecha 


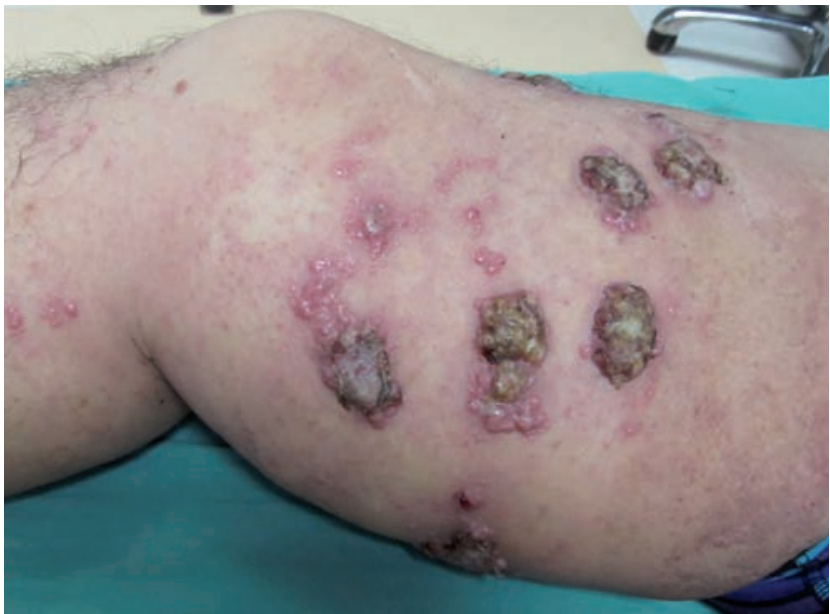

Figura 1

de instalación insidiosa. Con el tiempo, la lesión evoluciona, con cambio de color a blanquecina-grisácea, aumento de tamaño hasta $4 \mathrm{~cm}$ por $1.9 \mathrm{~cm}$, aspecto verrucoso y costroso, de borde irregular y aumento significativo de volumen de la extremidad comprometida. Posteriormente debido a ulceración y sangramiento consultó dermatólogo quien realiza biopsia la que informa: "neoplasia maligna de anexos cutáneos, concordante con porocarcinoma ulcerado desmoplásico con infiltración tumoral vascular linfática, e invasión del tejido adiposo subcutáneo llegando en su área superficial a $4,5 \mathrm{~mm}$ del margen quirúrgico lateral más cercano y $4 \mathrm{~mm}$ al margen profundo, con permeacion tumoral vascular linfática focal de un borde quirúrgico lateral".

Se deriva al Servicio de Oncología del Hospital Clínico Regional de Concepción, en noviembre del 2012, iniciando tratamiento con radioterapia localizada en región inguinal derecha, realizándose un total de 58 sesiones de radioterapia total (22 de electrones y 36 de fotones) entre noviembre y enero del 2013, tras lo cuales dado de alta con tratamiento paliativo para alivio del dolor.

Una semana después de finalizado dicho tratamiento, aparecen múltiples nódulos por debajo del área de la radioterapia de aproximadamente $2 \mathrm{~cm}$ de diámetro, agrupados, que evolucionan de forma similar a la lesión inicial.

En mayo de 2013 consulta en nuestro hospital por disnea súbita y dolor torácico tipo puntada en hemitórax izquierdo, que aumenta en inspiración. La radiografía de tórax evidenció derrame laminar izquierdo y los exámenes mostraron: Saturación 88\%, GSA: pCO2 44, pO2 54, HCO3: 27, Dímero D: 1513, Creatininemia: 0,88. En la evaluación dermatológica

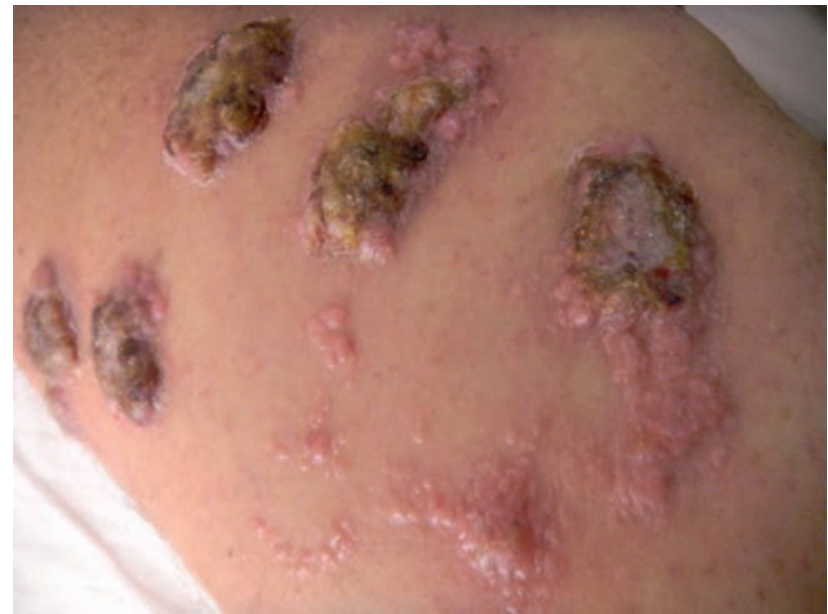

Figura 2

destacaban edema duro de toda la extremidad inferior derecha $(+++)$, lesiones tumorales múltiples en piel del muslo, (inferiores a región de radioterapia) ovaladas, de aspecto verrucoso y costroso de coloración café-negruzca implantadas en una piel eritematosa con aumento de la temperatura local (Figuras 1 y 2).

Se hospitaliza bajo sospecha de TEP, solicitándose ecodoppler de extremidad inferior derecha el que informa "Sin signos actuales de trombosis venosa profunda de extremidad inferior derecha. Importante edema de piel y celular subcutáneo de muslo y pierna derecha". El angioTAC de tórax informó cardiomegalia, leve derrame pleural bilateral, pulmones con signos de atrapamiento aéreo, asociados a algunos elementos focales de condensación pero fue negativo para tromboembolismo pulmonar, linfadenopatías mediastínicas inespecíficas a nivel de la ventana aortopulmonar, paratraqueales, subcarinales, perihiliares.

Ante la ausencia de TVP y TEP y la presencia de lesiones cutáneas se interconsulta a dermatología, donde se realiza biopsia de lesión de muslo derecho. Por sospecha de insuficiencia cardiaca congestiva se realiza ecocardiograma que concluye: "cavidades izquierdas no dilatadas con buena función global sistólica y diastólica, hipertensión pulmonar moderada, insuficiencia aórtica leve".

Equipo de broncopulmonar solicita TAC de tórax, abdomen y pelvis que describe "lesiones osteolíticas de aspecto secundario comprometiendo $7^{\circ}, 8^{\circ}$ y $10^{\circ}$ cuerpos vertebrales dorsales, diáfisis femoral derecha y ala iliaca izquierda. Nódulos pulmonares de lóbulos superiores de naturaleza indeterminada". 


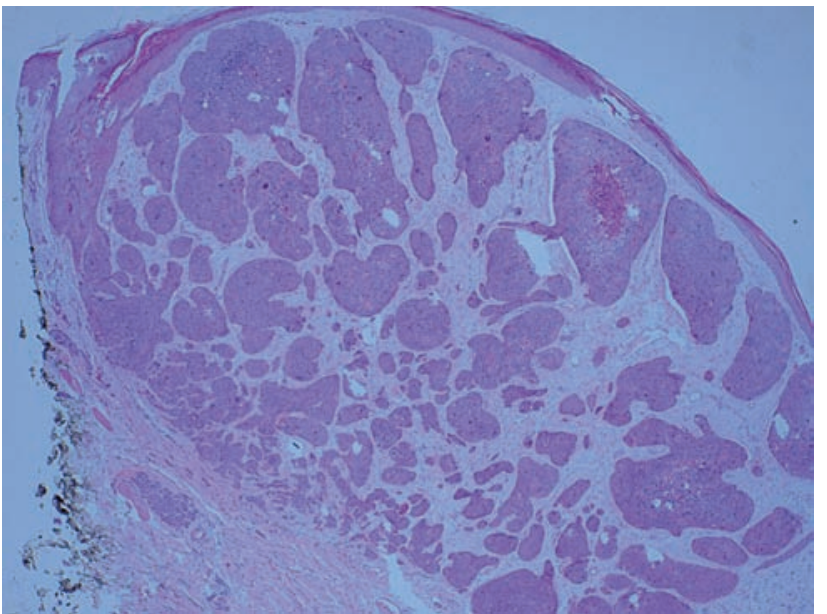

Figura 3

Se recibe informe de biopsia de piel que concluye "piel, con tumor epitelial de tipo anexial, concordante con porocarcinoma invasor. Invasión de dermis reticular. Permeación linfovascular extensa y compromiso de borde lateral de sección" (Figuras 3 y 4).

Se discute el caso en comité oncológico, decidiéndose el alta hospitalaria para continuar manejo en cuidados paliativos con radioterapia ambulatoria.

\section{Revisión de la literatura}

El porocarcinoma ecrino es un tumor infrecuente derivado del acrosiringio de las glándulas sudoríparas ecrinas. Afecta por lo general a personas mayores de 65 años, sin predominio de sexo. La clínica no es característica, por lo general se trata de una lesión única que puede ser descrita como placa verrucosa, nódulo o lesión polipoidea de tamaño variable desde $4 \mathrm{~mm}$ hasta $20 \mathrm{~cm}$ de diámetro, con una media de $2 \mathrm{~cm}$. Frecuentemente los tumores se encuentran ulcerados pudiendo sangrar con traumatismos mínimos.

La patogénesis de este tumor aún es desconocida, aunque en varios casos se ha asociado a una sobreexpresión de la proteína p16. La proteína p16 es una proteína codificada por el gen supresor tumoral CDKN2A, localizado en el cromosoma 9 y que actúa como inhibidor de las cinasas dependientes de ciclinas que desaceleran el ciclo celular actuando en el punto de control fase $\mathrm{G} 1$-fase $\mathrm{S}$ mediante la inactivación de la proteína codificada por el gen del retinoblastoma ( $\mathrm{pRb}$ ). Existe, por tanto, una relación recíproca entre pRb y $\mathrm{p} 16$. Mediante inmuhistoquímica se ha encontrado una inactiva-

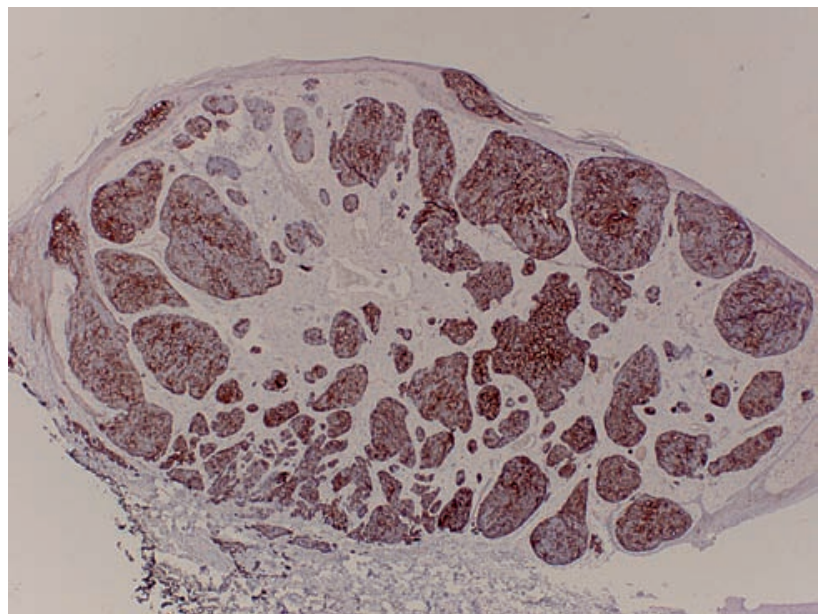

Figura 4

ción tanto de p53 como de pRb, que se corresponde con una sobreexpresión de 16 en los pacientes portadores de porocarcinoma ecrino ${ }^{7}$.

En el estudio histopatológico se visualizan amplios cordones anastomóticos y columnas sólidas de células grandes que se extienden hacia el interior de la dermis hasta diferentes niveles. Se observan características citológicas de malignidad como núcleos pleomórficos e hipercromáticos y actividad mitótica anormal. Pueden existir áreas de células claras, diferenciación escamosa, pigmento melánico y necrosis focal en las masas dérmicas además de estructuras ductales. Las células contienen cantidades variables de material PAS positivo, siendo gran parte lábil a la diastasa. Se tiñen positivamente para antígeno carcinoembrionario (CEA), citoqueratinas y antígeno epitelial de membrana (EMA). Son positivas también para amilofosforilasa y succinil deshidrogenasa ${ }^{8,9}$. Robson y colaboradores, en un estudio de 69 casos, describieron factores de mal pronóstico: células con más de 14 mitosis por campo de alto poder, con invasión linfovascular y profundidad mayor de $7 \mathrm{~mm}$ que evolucionan con un curso clínico más agresivo ${ }^{6}$.

El porocarcinoma ecrino puede presentar metástasis cutáneas, linfáticas o viscerales en pulmón, retroperitoneo, huesos largos, mama, vejiga, peritoneo, pericardio, ovario e hígado $0^{9,10}$.

El diagnóstico diferencial clínico debe hacerse con carcinoma epidermoide, melanoma amelánico, enfermedad de Bowen y granuloma telangiectásico entre otros. El tiempo de evolución es normalmente prolongado y la lesión maligna puede presentarse a partir de un poromaecrino previo ${ }^{11}$. 
El carcinoma epidermoide se caracteriza clínicamente por presentarse preferentemente en zonas fotoexpuestas en paciente añoso, con antecedentes de fotoexposición, como pápulas, placas o nódulos de color rosado o rojo, con una superficie lisa, queratósica o ulcerada y suelen ser lesiones friables que pueden sangrar con mínimos traumatismos.

El melanoma amelánico corresponde a lesiones maculares, con borde irregular, de tamaño variable, con crecimiento inicialmente vertical y lento que luego se hace horizontal y rápido, apareciendo un nódulo que clínicamente no presenta pigmentación evidente.

La enfermedad de Bowen se presenta como placas descamativas solitarias, bien delimitadas, de color entre rosa y rojo intenso y suelen aparecer en zonas expuestas al sol.

El granuloma telangiectásico tiene el antecedente de ser post traumático y clínicamente se presenta como pápula de crecimiento rápido, friable y rojizo, de muy fácil sangramiento al mínimo roce ${ }^{11,12}$.

El tratamiento de elección del porocarcinoma es la extirpación quirúrgica amplia, con cirugía micrográfica de Mohs. Con esta técnica, diversos estudios han reportado tasas de curación en un $70 \%$ a $80 \%$ de los casos y de recurrencia de $17 \%$ a $30 \%$ con diseminación linfática de $19 \%$ a $50 \%$ y metástasis distantes en $9 \%$ a $33 \%$. Lesiones grandes, multinodulares, ulceración y crecimiento rápido pueden asociarse con recurrencia local y enfermedad metastásica. Algunos autores recomiendan la realización de linfadenectomía regional profiláctica en casos de recurrencia local, pobre diferenciación tumoral o infiltración linfática ${ }^{13}$. El tratamiento de los pacientes que presentan metástasis suele ser difícil. La radioterapia es poco efectiva y en ocasiones es necesario combinarla con quimioterapia siendo los agentes utilizados más comúnmente el 5-fluorouracilo, doxorrubicina, mitomicina $\mathrm{C}$, vincristina, cisplatino, bleomicina y docetaxel, los cuales en general se utilizan en combinación, reportándose remisiones parciales y en ocasiones completas y prolongadas ${ }^{14,15}$.

\section{Referencias bibliográficas}

1. Rosai J Rosai y Ackerman's Surgical Pathology. Novena Edición. Mosby Eds. China. 2004; 140-154.

2. Weedon D, Sarasin A y Burg G. Skin tumours. Pathology and Genetics of. Who. Lyon. Le Bort 2006; 121-163.

3. Zappi E. Dermatopatología. Clasificación y estudio razonado de las lesiones cutáneas. Primera Edición. Ascune Hnos. Buenos Aires. Argentina. 2007; 196-210.

4. Mercadillo-Pérez $P$ et al. Porocarcinoma ecrino. RevMedHosp Gen Mex 2010; 73 (1): 39-42.

5. Bleier BS, Newman JG, Quon H, Feldman MD, Kent KK, et al. Eccrineporocarcinoma of the nose. Arch Otolaryngol Head Neck Surg. 2006; 132(2):215-218

6. Robson A, Greene J, Ansari N, Kim B, Seed PT, et al. Eccrineporocarcinoma:a clinicopathologic study of 69 cases. Am SurgPathol. 2001; 25 (6): 710-720.

7. Gu LH, Ichiki Y, Kitajima Y. Aberrant expression of $p 16$ and RB protein on eccrine porocarcinoma. J Cutan Pathol. 2002; 29(8):473-479.

8. Lozano J, Andueza J, Valcayo A. Porocarcinoma Ecrino: un tumor cutáneo infrecuente con alta incidencia en Navarra. Sitio en Internet. Disponible en: http://www.cfnavarra.es/salud/d/anotes/textos/

9. Goel R, Contos MJ, Wallace ML. Widespread metastatic eccrine porocarcinoma. J Am Acad Dermatol. 2003; 49(5 Suppl):S252-254.

10. Sergio GC, Ignacio DC, Roberto G, Gastón C. Porocarcinoma ecrino epidermotropo. Dermatol Argent.2004;10(2):104-108.

11. Bolognia J, Jorizzo J, Rapini R. Dermatología. Mosby Ed, primera edición, 2004. p. 1674-1676,1680-1681,1794, 1823-1824.

12. Gerber PA, Schulte KW, Ruzicka T. Eccrineporocarcinoma of the head: An important differential diagnosis in the elderly patient. Dermatology. 2008; 216 (3): 229-233.

13. Cruz-Benítez $L$, et al. Porocarcinomaecrino. Informe de un caso y revisión de la bibliografía. GAMO Vol. 9 Núm. 6, noviembre - diciembre 2010

14. Plunkett TA, Hanby AM, Miles DW, Rubens RD. Metastaticeccrineporocarcinoma: Response todocetaxel (Taxoterechemotherapy). Ann Oncol. 2001; 12(3): 411-414.

15. de Bree E, Volalakis E, Tsetis D, Varthalitis Y, Panagiotidis J, et al. Treatment of advanced malignant eccrine poroma with loco-regional chemotherapy. $\mathrm{Br}$ J Dermatol. 2005;152(5):1051-1055. 